\title{
Constructing Reliable Skin Detector Based on Combining Texture and Color Features
}

\author{
Alaa Yaseen Taqa \\ Department of Computer Science \\ College of Education \\ University of Mosul
}

\author{
Hamid A. Jalab \\ Department of Computer \\ System and Technology \\ University of Malaya
}

Received
$29 / 09 / 2010$
Accepted

02 / 03 / 2011

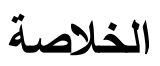

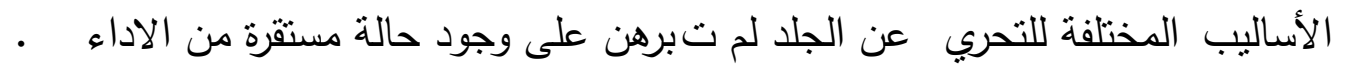

ويعزى هذا الى لون الجلد بالصورة يتحسس لتغيرات الإضاءة ، تضبيط الكاميرا وأنواع الجلد

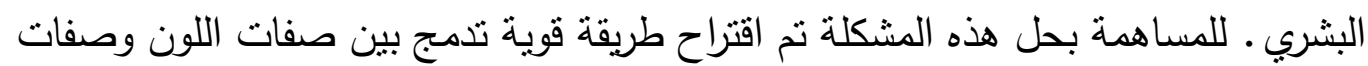
النسيج. نم احتساب وتخمين صفات النسيج باستخدام المقاييس الإحصائية كالمدى، الانحراف

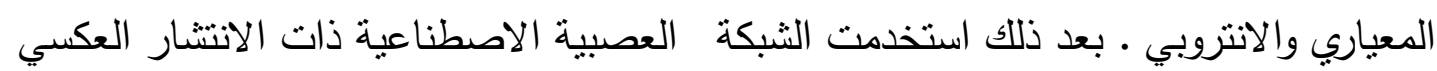

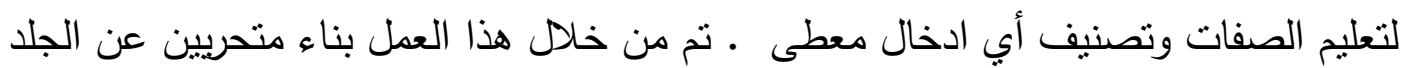

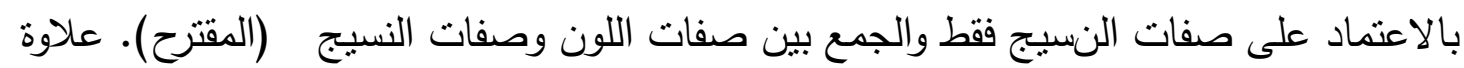

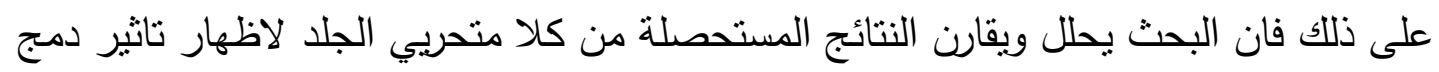
الصفات اللونية والنسيجية معا على مستوى قوة المتحري وجد ان طريقة الكثف عن الجلد

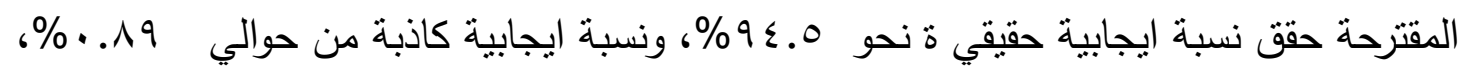

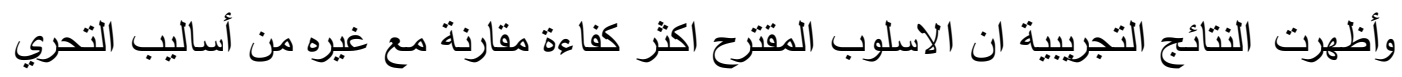
عن الجلد المستتدة عل النسيج.
\end{abstract}

\begin{abstract}
Various approaches of skin detection have yet to demonstrate a stable state of performance. This is due to skin color in an image that is sensitive to variant illumination, camera adjustments, and human skin types. To contribute in overcome this problem a robust skin detection method that integrates both color and texture features is proposed. Texture features were estimated using statistical measures as range, standard deviation, and entropy. Back-propagation artificial neural
\end{abstract}


network is then used to learn features and classify any given inputs. In this work, two skin detectors based on texture features only, and a combination of both color and texture features (proposed) have been constructed. Furthermore, the paper analyzes and compares the obtained results from the both skin detectors to show the impact of the integrating color and texture features to the robustness level. It found that the proposed skin detection method achieved a true positive rate of approximately $94.5 \%$ and a false positive rate of approximately $0.89 \%$. Experimental results showed that proposed approach is more efficient compared with other state-of-the-art texture-based skin detector approaches.

Keywords: Skin detector, Back Propagation ANN, Image texture features, Image segmentation.

\section{Introduction}

Skin detection is one of the important techniques in image processing and the most distinctive and widely used key to many applications such as face detection [1], various medical applications [2], human motion analysis [3] , naked images filters [4], and others. Skin detection is used to determine the image pixels related to human skin. Color is a useful cue to extract skin pixels. One of the major issues in using skin color in skin detection is how to choose a suitable color space. Numerous color models (RGB, CMY, and CMYK [5]; Hue, Saturation, and Intensity (HIS) [6, 7]; Hue, Saturation, and Value (HSV) [8]; Normalized RGB [9]; and $\mathrm{YCbCr}$ $[6,8]$ ) are used today because color science is a broad field encompassing many areas of applications. Many skin models have been developed based on color feature only using RGB color model [10], but these approaches are not robust enough to handle different lighting conditions and complex backgrounds containing surfaces and objects with skin-like colors. Many researchers as $[11,12]$ have used pixel-based algorithms as main methods for skin detection. This approach is easy but it is not accrue enough. Nevertheless, few skin detection methods have been constructed based on a pixel and its neighbors [13]. Some researchers have used traditional techniques $[14,15,16]$, while others used intelligence $[17,18$, 19] to detect skin pixels. Skin color is considered as a useful and discriminating spatial feature for many applications, but it is not robust enough to deal with complex image environments. Skin tones range from dark (Africans) to light white (Caucasians ) as shown in Figure 1. In addition, both the light-changing conditions (see Figure. 2 a) and the existence of objects with skin-like colors could cause some major difficulties (see Figure $2 \mathrm{~b}$ ). To help in overcome these problems, this paper proposes a robust skin detection using (ANN) Artificial Neural Network that integrates both color and texture features. It involves the information of a pixel and its neighbors. 


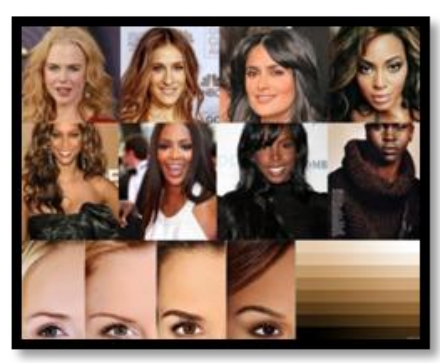

Figure 1: Different Skin Colors

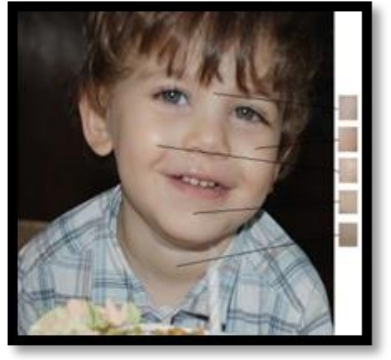

a

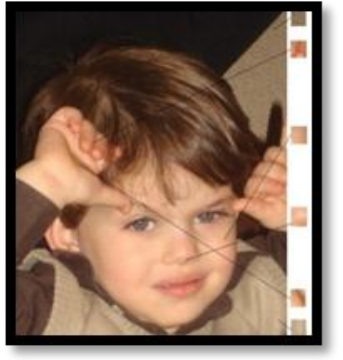

b

Figure 2: Different skin and skin-like colors (b) in variant lighting conditions (a)

Table 1 illustrates several publications using different approaches for skin detection. The rest of the paper is organized as follows: Section 2 illustrates the texture features; Section 3 presents the proposed skin detection method in details; Section 4 describes the results obtained from the two skin detectors; and Section 5 presents the evaluations of each detector. The last two sections contain the discussion and conclusion and suggestions for future work respectively.

Table 1: Different publications of skin detection

\begin{tabular}{|c|c|c|}
\hline Reference/Author/Year & Paper Title & \\
\hline [20] Ahmed et al. 2007 & $\begin{array}{l}\text { A robust fuzzy logic based } \\
\text { approach for skin detection in } \\
\text { colored images }\end{array}$ & $\begin{array}{l}\text { Fuzzy logic using different color } \\
\text { model }\end{array}$ \\
\hline $\begin{array}{l}\text { Almohair et al. } \\
2007\end{array}$ & $\begin{array}{l}\text { Skin Detection in Luminance } \\
\text { Images using Threshold Technique }\end{array}$ & $\begin{array}{llll}\begin{array}{l}\text { Threshold } \\
\text { detection }\end{array} & \text { values } & \text { based } & \text { skin } \\
\end{array}$ \\
\hline [22] Jiang et al. 2007 & $\begin{array}{l}\text { Skin Detection Using Color, } \\
\text { Texture and Space Information }\end{array}$ & $\begin{array}{l}\text { Integrate color, texture and space } \\
\text { information. Using gabor filter }\end{array}$ \\
\hline [23] Abin et al. 2008 & $\begin{array}{l}\text { Skin Segmentation based on } \\
\text { Cellular Learning Automata }\end{array}$ & $\begin{array}{l}\text { Combining color and texture } \\
\text { information of skin with cellular } \\
\text { learning automata }\end{array}$ \\
\hline $\begin{array}{l}\text { [24] Al-Wadud et al. } \\
2008\end{array}$ & $\begin{array}{l}\text { A Skin Detection Approach Based } \\
\text { on Color Distance Map }\end{array}$ & DM based on gray scale images \\
\hline $\begin{array}{l}\text { [25] Conci and Nunes } \\
2008\end{array}$ & $\begin{array}{l}\text { Comparing color and texture - } \\
\text { based algorithms for human skin } \\
\text { detection }\end{array}$ & $\begin{array}{l}\text { Skin detection based on texture } \\
\text { feature using different color spaces }\end{array}$ \\
\hline [15] Ghouzali et al. 2008 & $\begin{array}{l}\text { A skin detection algorithm based } \\
\text { on discrete cosine transform and } \\
\text { generalized Gaussian density }\end{array}$ & $\begin{array}{l}\text { Skin model based on generalized } \\
\text { Gaussian density }\end{array}$ \\
\hline [26] Fotouhi et al. 2009 & $\begin{array}{l}\text { Skin Detection using Contourlet- } \\
\text { Based Texture Analysis }\end{array}$ & $\begin{array}{l}\text { Color and texture based on wavelet } \\
\text { domain using neural network }\end{array}$ \\
\hline [27] Zafarifar et al. 2010 & $\begin{array}{l}\text { Improved Skin Segmentation for } \\
\text { TV Image Enhancement,Using } \\
\text { Color and Texture Features }\end{array}$ & $\begin{array}{l}\text { Defined in HSV color space and } \\
\text { versus a histogram-based color } \\
\text { detector and extract texture feature }\end{array}$ \\
\hline $\begin{array}{l}\text { [18] Al Abbadi and et al } \\
2010\end{array}$ & $\begin{array}{l}\text { Psoriasis Detection Using } \\
\text { Color and Texture Features }\end{array}$ & $\begin{array}{l}\text { Skin disease diagnosis system } \\
\text { based on skin color and texture } \\
\text { using artificial neural network }\end{array}$ \\
\hline [19] Taqa and Jalab 2010 & $\begin{array}{l}\text { Increasing the Reliability of Fuzzy } \\
\text { Inference System-Based Skin } \\
\text { Detector }\end{array}$ & $\begin{array}{l}\text { Texture features based on the RGB } \\
\text { color space using fuzzy inference } \\
\text { system }\end{array}$ \\
\hline $\begin{array}{l}\text { [28] Doukim and et al } \\
2011\end{array}$ & $\begin{array}{l}\text { Combining Neural Networks for } \\
\text { Skin Detection }\end{array}$ & $\begin{array}{l}\text { Multilayer perceptron using } \mathrm{YcbCr} \\
\text { color space model. }\end{array}$ \\
\hline
\end{tabular}




\section{Extracting Texture Features}

Three texture features were estimated using a statistical approach, which computes the different properties through three statistical measures: standard deviation, maximum-minimum range, and entropy. These features were extracted from each pixel and its neighbors. The standard deviation could be calculated using the following formula [29]:

$S=\left(\frac{1}{n} \sum_{i=1}^{n}\left(x_{i}-\bar{x}\right)^{2}\right)^{\frac{1}{2}}$

Where,

$\overline{\boldsymbol{x}}=\frac{1}{n} \sum_{\mathrm{i}=1}^{\mathrm{n}} \mathrm{x}_{\mathrm{i}}$

Meanwhile, the maximum-minimum range equals (maximum value of pixel - minimum value of pixel) of the $n$-by- $n$ neighborhood around the corresponding pixel in input image I [5]. Finally, the entropy was estimated by using the formula [5]:

$\mathrm{E}=\sum_{\mathrm{i}=1}^{\mathrm{n}} \mathrm{P}\left(\mathrm{x}_{\mathrm{i}}\right) * \log _{2}\left(\mathrm{P}\left(\mathrm{x}_{\mathrm{i}}\right)\right)$

where, $P\left(x_{i}\right)$ is the probability of the pixel color $\left(x_{i}\right)$, and $n$ represents the number of pixels.

\section{The Proposed Skin Detection Method}

The proposed skin detection method -based on ANN- combines both color and texture features. To increase the reliability of the skin detection process, neighborhood pixel information is incorporated into the proposed method. The color features are extracted directly from the pixels using RGB model, and the texture features of the scanned windows over the image pixels are extracted using a statistical approach then feature vector of pixels and their 8 neighbors is produced. To determine the decision rule of these features, a multilayer back-propagation ANN [30] [31] is used. The architecture of the used back propagation ANN (see Figure 3) consists of: one input layer, two hidden layers and one output layer. There are six neurons (nodes) in the input layer, each one representing one feature of the feature vector; three and two neurons in the two hidden layers respectively; and one neuron in the output layer, which equals to (1) when the input features represent the skin region, and (0) when the input features represent non-skin regions. The block diagram of the proposed skin detection method is shown in Figure 4.

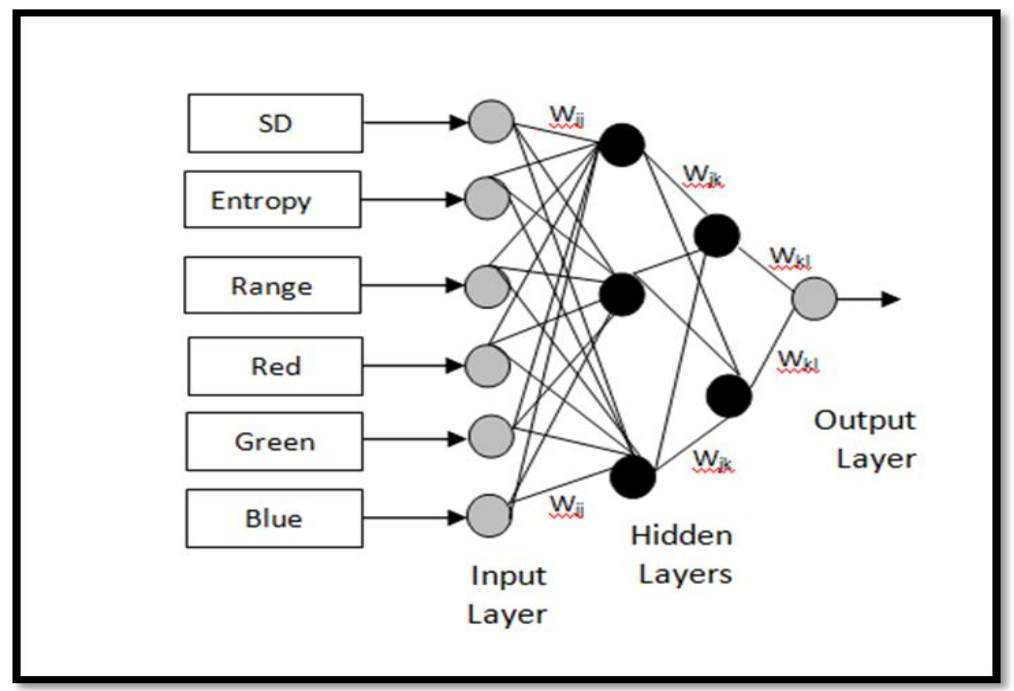

Figure 3: The topology of the used back-propagation ANN 


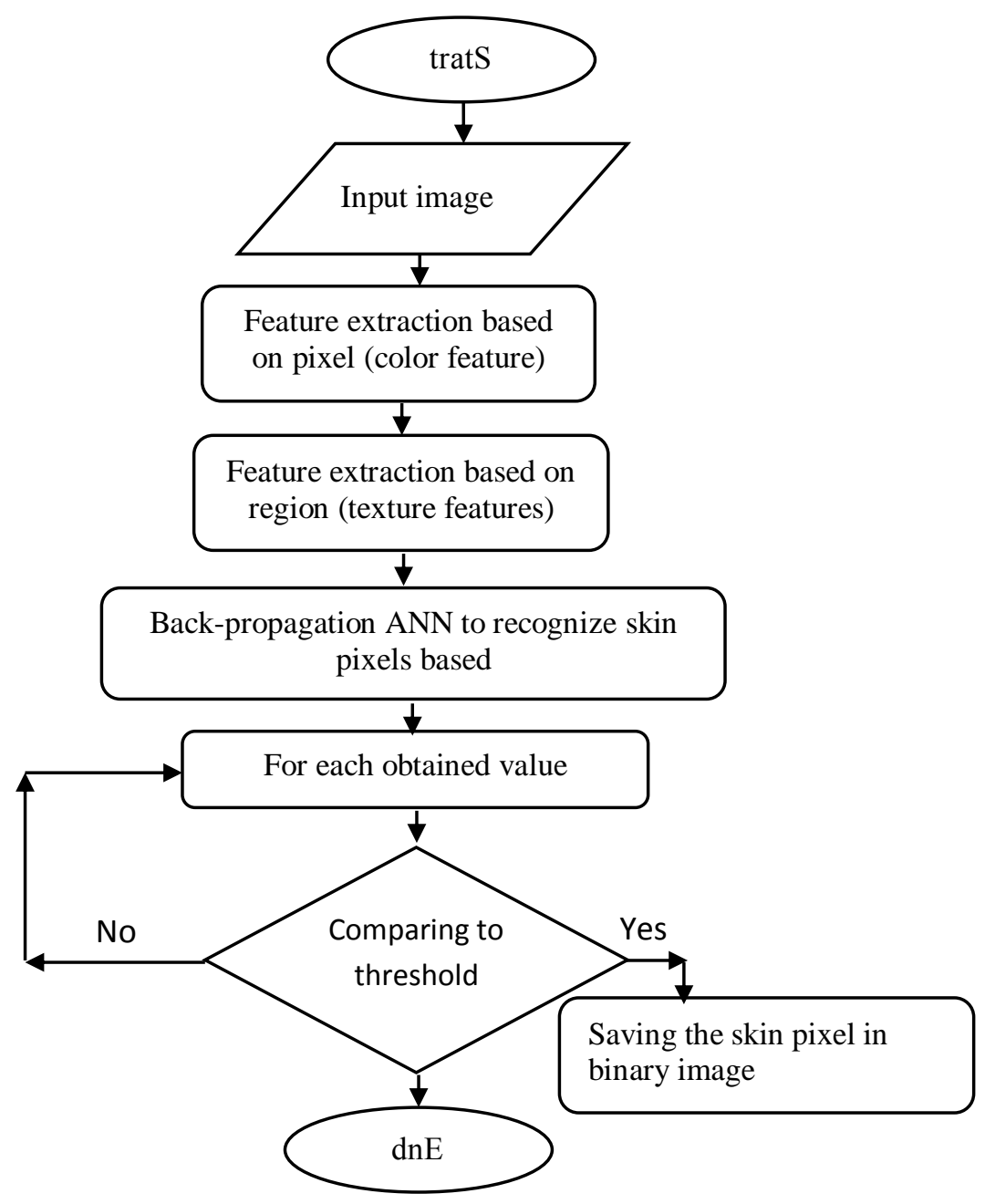

Figure: 4 The proposed skin detection method

The proposed skin detection method consists of the following phases:

1. Initial phase: It consists of two main steps:

- Creation of skin and non-skin image database: This step involves collecting samples of different human skin-colored pixels from a variety of people under different illumination conditions (skin pixels without background), as well as a variety of non-skin colored pixels. The image is examined manually to determine whether it contains skin. If no skin is present, the image is placed in the non-skin group. In the skin image group, regions of skin pixels are manually extracted using Adobe Photoshop. In labeling skin, an attempt is done to exclude the eyes, hair, clothes, mouth opening, and lips. The collected data are divided into three subsets: training, validation, and testing. The training set is used as the primary set of data applied to the ANN for learning and adaptation, with 351228 skin and 428602 non-skin pixels manually segmented from 87 images. The validation set is used to further refine the ANN construction and is considered an important guard. The test set includes different images with simple and complex backgrounds, indoor and outdoor settings, and different image sizes and skin colors used to measure the performance of the ANN. It has 1119129 different pixel types manually segmented from 95 images. 
- Feature Extraction: Throughout feature extraction step, two windows are moved over an image; the size of the first window is $3 \times 3$ and that of the second is $9 \times 9$. The color features (Red, Green, and Blue) of the centered pixel of the first window are extracted. The texture features are extracted using a statistical approach, in which different properties are computed using standard statistical measures as standard deviation, range, and entropy. The first two static features are estimated from pixels within the first window, whereas entropy is estimated from the pixels within the second window. All the statistical measures are computed for multi-channel image matrices (Red, Green, and Blue), and their average is considered as the final representation of the feature. Figure 5 shows (for example) the scheme of computing entropy for multi-channel image matrices.

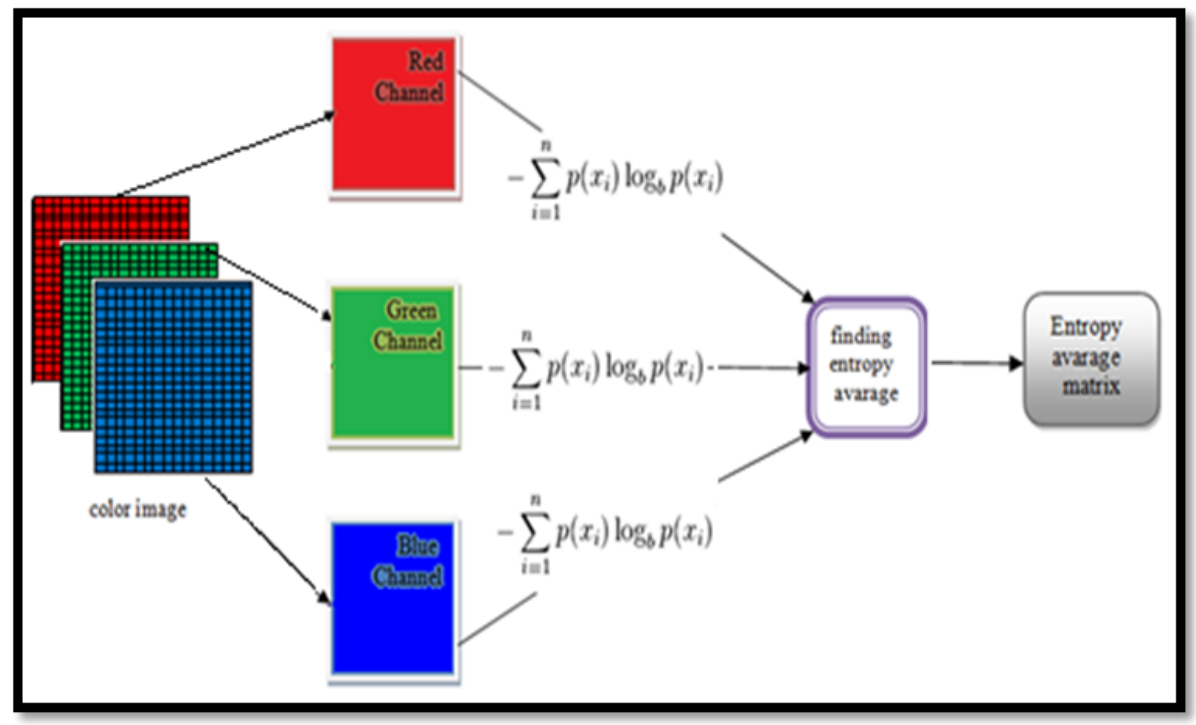

Figure: 5 Computing scheme entropy for colored image

Entropy is a statistical measure of randomness that can be used to characterize the texture of the input image [5].Entropy for each channel is defined as:

$\mathrm{E}_{\mathrm{r}}=\sum_{\mathrm{i}=1}^{\mathrm{n}} \mathrm{P}_{\mathrm{r}}\left(\mathrm{x}_{\mathrm{i}}\right) * \log _{2}\left(\mathrm{P}_{\mathrm{r}}\left(\mathrm{x}_{\mathrm{i}}\right)\right)$
$\left.\mathrm{E}_{\mathrm{g}}=\sum_{\mathrm{i}=1}^{\mathrm{P}_{\mathrm{g}}} \mathrm{P}_{\mathrm{i}}\right) * \log _{2}\left(\mathrm{P}_{\mathrm{g}}\left(\mathrm{x}_{\mathrm{i}}\right)\right)$
$\mathrm{E}_{\mathrm{b}}=\sum_{\mathrm{i}=1}^{\mathrm{n}} \mathrm{P}_{\mathrm{b}}\left(\mathrm{x}_{\mathrm{i}}\right) * \log _{2}\left(\mathrm{P}_{\mathrm{b}}\left(\mathrm{x}_{\mathrm{i}}\right)\right)$

The average entropy matrix will be:

$$
\mathrm{E}=\frac{\mathrm{E}_{\mathrm{r}}+\mathrm{E}_{\mathrm{E}}+\mathrm{E}_{\mathrm{b}}}{3}
$$

2. Training phase: To train the neural network for detecting skin pixels, the extracted features are entered as training input data into the ANN. The quality of the training sets entered into the network determines how well the detector performs. The input image may contain objects other than skin; thus, the detector is trained and learned to recognize skin and nonskin features. The weight matrices between the input and the hidden and output layers are initialized with random values. After repeatedly presenting features of the input samples and desired targets, we compare 
the output with the desired outcome, followed by error measurement and weight adjustment until the correct output for every input is attained. Furthermore, the neurons of the two hidden layers are estimated using hyperbolic tangent sigmoid transfer function, whereas the output layer neuron is estimated using linear transfer function. The training algorithm used is Gradient descent with momentum back propagation. The training phase of the skin detector is illustrated in Figure 6. To select the significant contribution of increasing the accuracy of the skin detector, two different types of skin detectors are constructed in this paper: those using texture features based skin detection and a combination of texture features with color feature-based skin detection.

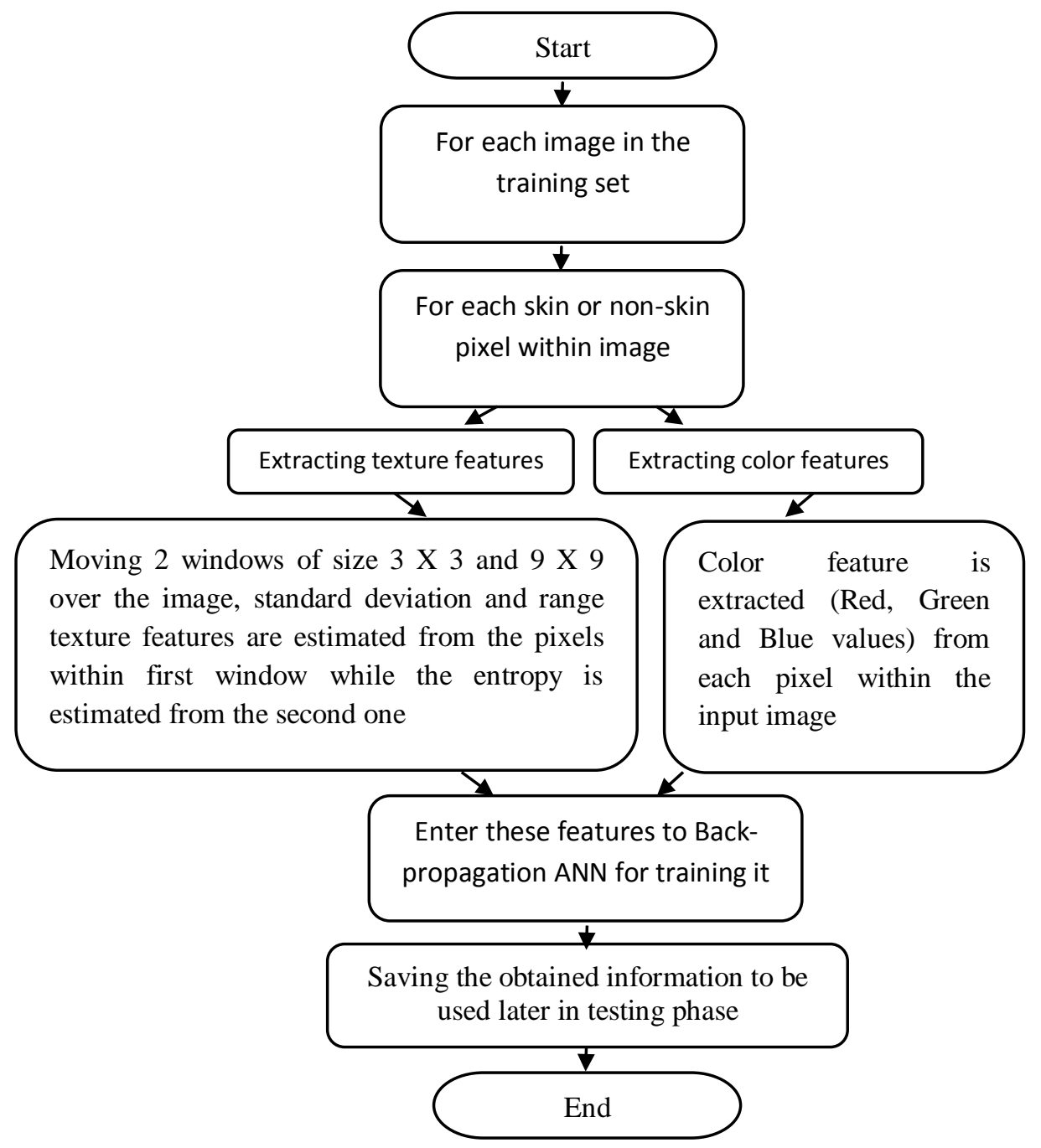

Figure 6: Training phase of the proposed skin detector

3. Testing phase: The skin detector is used to test each pixel of a given image (test image) depending on training data. If a pixel is detected as skin, it will be stored in a new image (skin image) at the position of the original image. After examining all image pixels, a new binary image is obtained, which includes only skin pixels. The obtained results from this phase are used to evaluate the performance of the proposed skin detector. The testing phase of the skin detector is illustrated in Figure 7. 


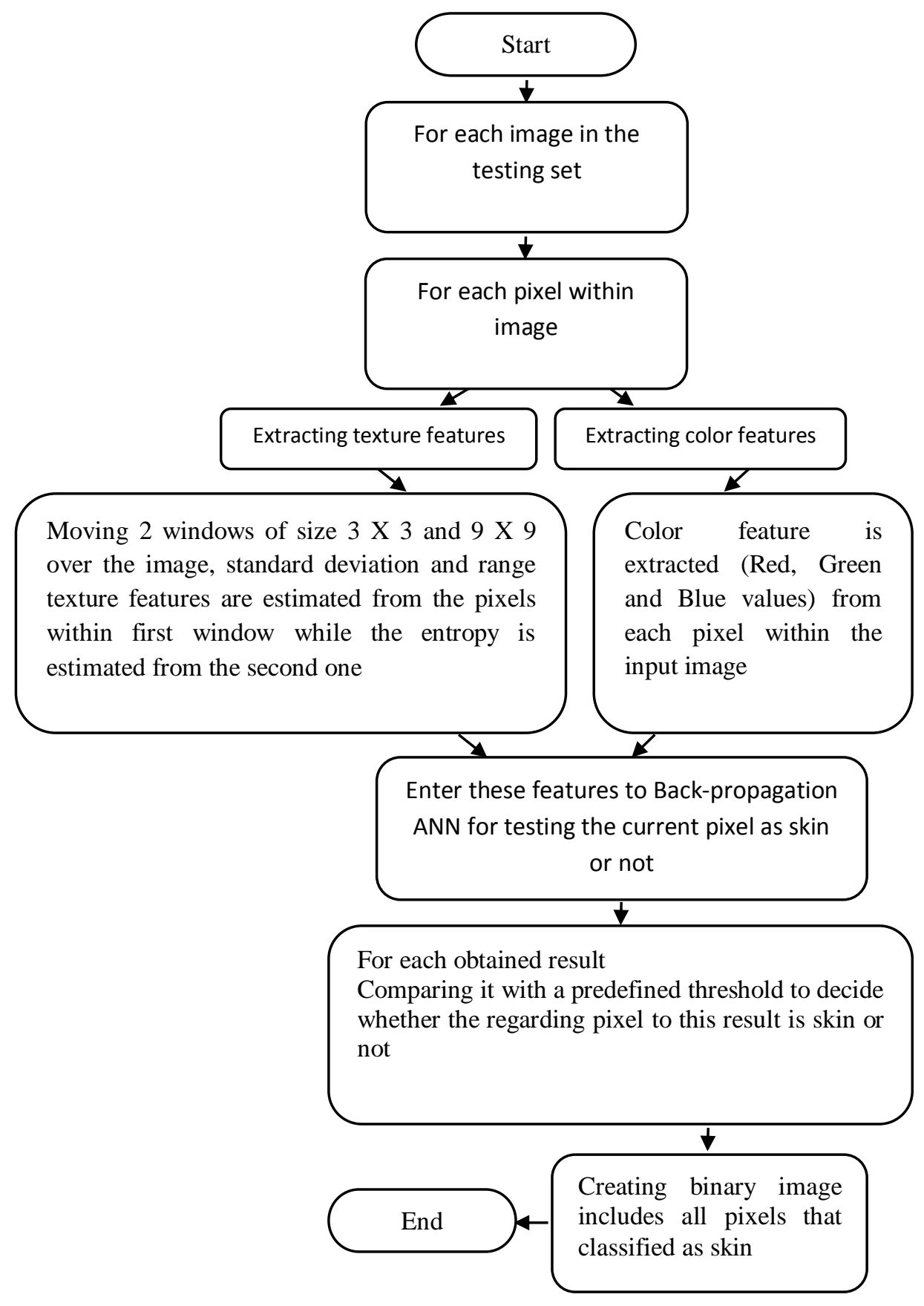

Figure 7: Testing phase of the proposed skin detection method

\section{Results}

The experimental results are presented to show the effectiveness of the proposed skin detector which is based on integrating both texture and color features. Our skin detection system was carried out on a $3.00 \mathrm{GHz}$ Intel (R) Core TM 2Duo processor with 8 GB RAM on Windows Vista platform using MATLAB R2009b.

The implementation of the skin detector has been tested in different images with simple and complex backgrounds, indoor and outdoor settings, as well as different image sizes and skin colors. The experiment is performed on the testing set, which includes 1119129 uncontrolled (different illumination, captured quality, distance to camera, etc.) pixels. 
Each of the first 608129 pixels belongs to an arbitrary number of skin images and images containing an arbitrary number of people and faces. The other 511000 pixels reflect no skin pixels, and pixels belonging to images with objects that present skin-like tones (such as a red flower, dog, chocolate, etc.) are included as well.

Figure 8 shows the overlap between skin and non-skin colors, suggesting that the skin detection problem based on color features is a difficult issue because a significant overlap exists between the skin and non-skin models. However, overlap is a significant problem only if the counts in the shared bins are comparable in the skin and non-skin cases. The effect of this problem can be minimized using the texture analysisbased features.

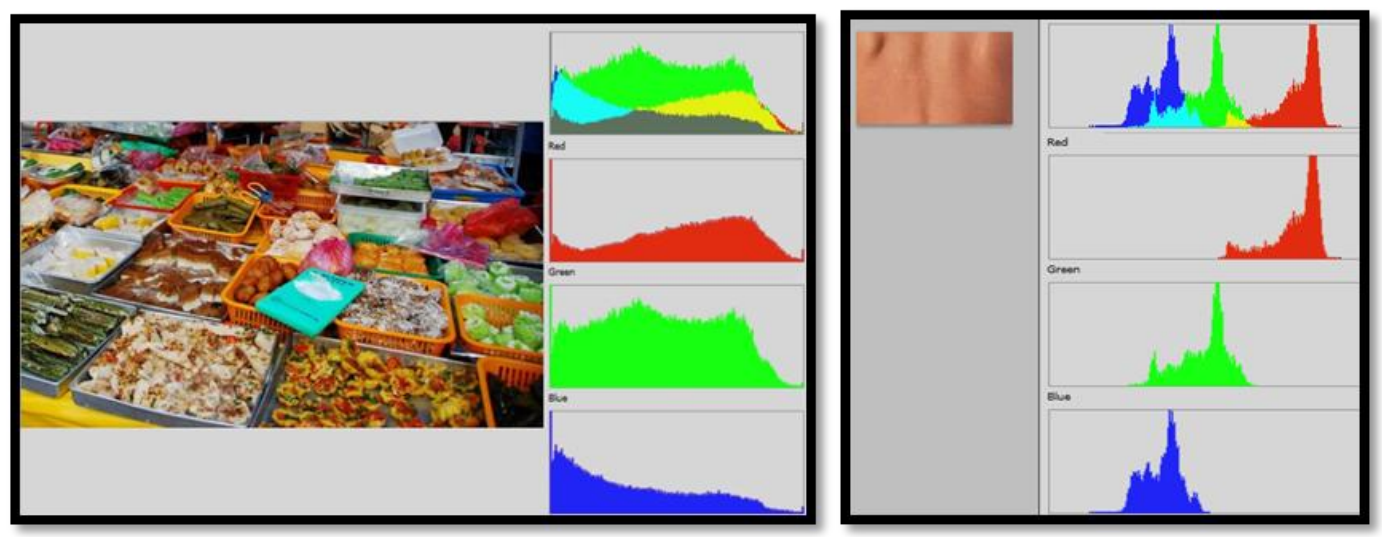

Figure 8: Skin and non-skin image histograms

Two different skin detectors have been tested and evaluated to select the one with higher reliability; then, the evaluations are compared with the performance of previous skin detectors. The first skin detector method recognizes skin pixels based only on texture features; and the second one detects the skin pixels by combining both texture and color features. The testing result of the skin detector based on ANN with texture features only are shown in Figure 9, including high rates of false positives and false negatives, caused by using only texture features.
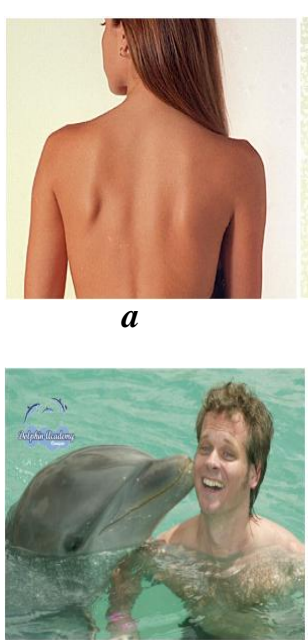

g
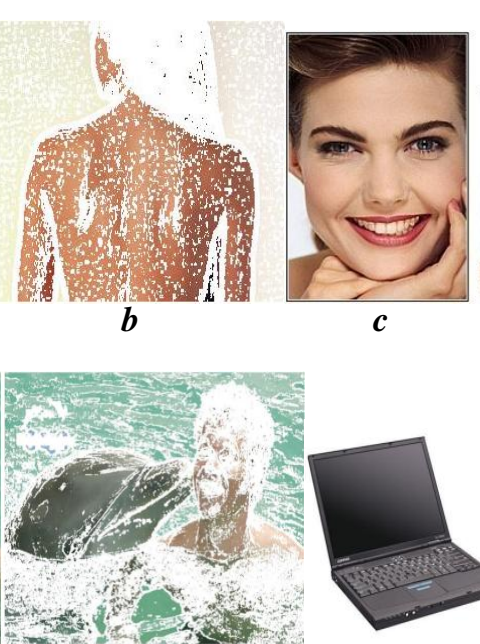

$\boldsymbol{h}$

$i$
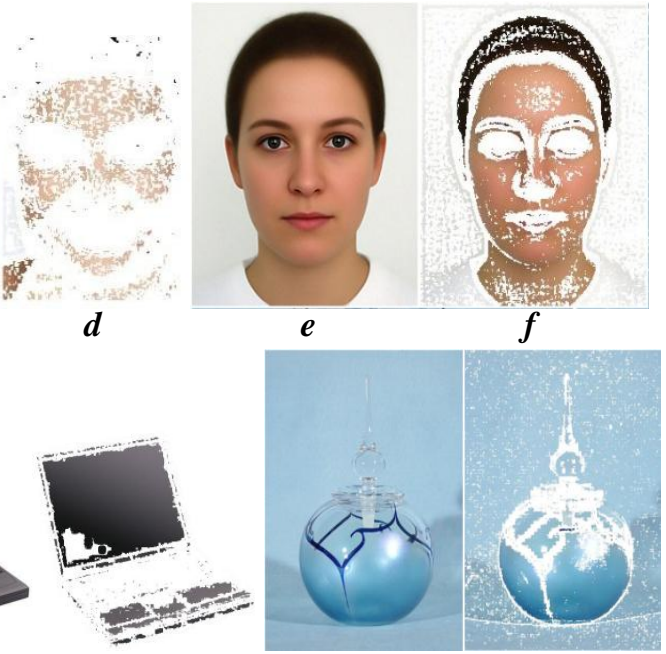

$k$

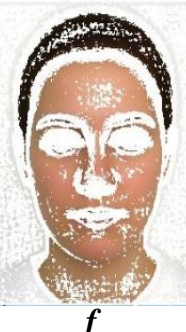

$f$

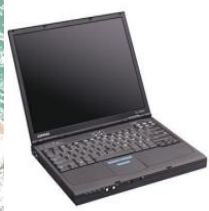

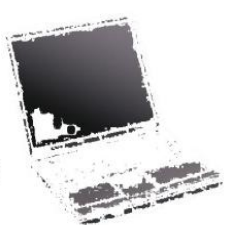

$j$ $l$

Figure 9: Results of testing skin detector using ANN based on texture features only 
Many skin regions with different colors noticeably have the same texture; thus, obtaining highly accurate detection rates based only on texture features is impossible. Figure 10 show that different pixel regions (skin and non-skin) have a variety of colors with similar textures. Some of which (Figures $10 \mathrm{a}, \mathrm{b}, \mathrm{d}$, and e) have been detected incorrectly using ANN with only texture features.

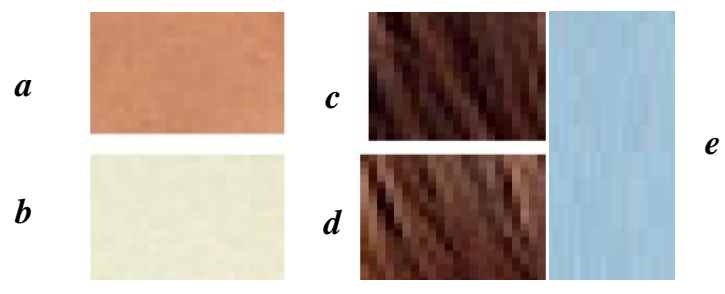

Figure 10: Different pixel regions have variety colors with similar texture

The testing result of our proposed skin detector based on ANN, combining both texture and color features, is illustrated in Figure 11. The results include high rates of true positives and true negatives with low rates of false detection. Although the image in Figure 10 reflects several human skin types with different colors and textures, the skin pixels within this image are detected correctly by the proposed skin detector, except for a few scattered pixels incorrectly detected as non-skin. Most skin pixels within the images shown in Figure 11.a,c, and e are detected correctly (Figure 11.b), while no false detection rates are shown within images $i$ and $\mathrm{j}$ in Figure 11. More additional example shows that most skin pixels with different colors as shown in Figure $11 \mathrm{~g}$ are detected correctly (Figure $11 \mathrm{~h}$ );

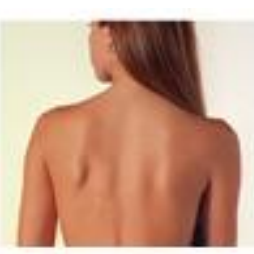

$\boldsymbol{a}$

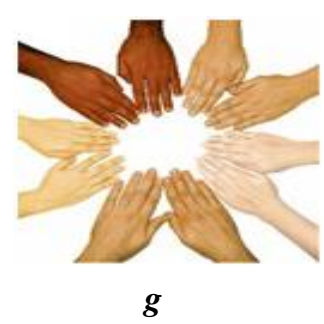

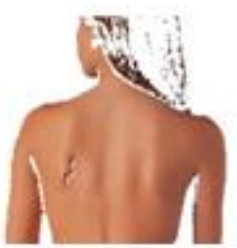

$b$

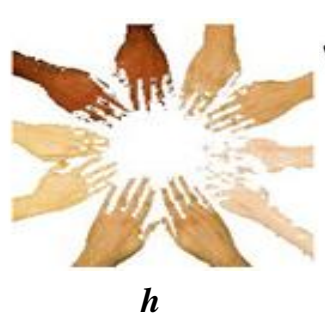

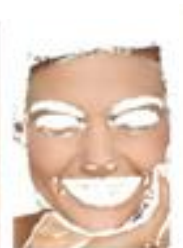

$d$

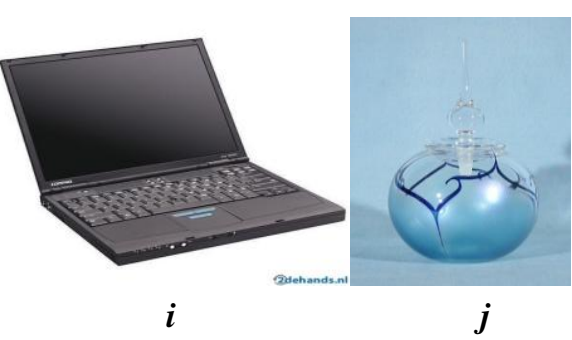

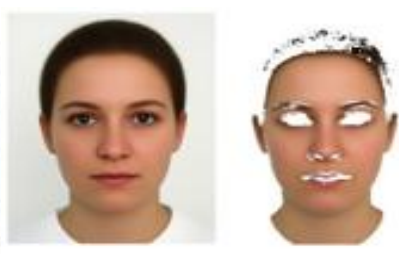

$f$

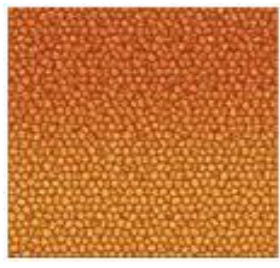

$\boldsymbol{k}$

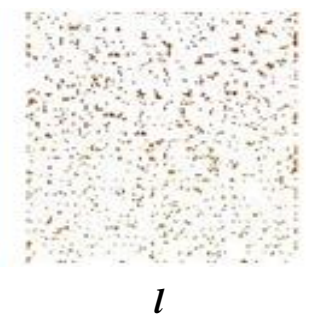

$l$

Figure 11: Results of testing our proposed skin detector using ANN based on combining both texture and color features 
More problematic are images with wood, copper-colored metal, or chocolate colors as they contain shades often occurring in the skin model and are difficult to reliably discriminate using only color or texture features. The combination of both features results in fairly dense sets of true positives; however, the image shown in Figure 111 versus its original (Figure $11 \mathrm{k}$ ) is correctly classified because it is very similar to skin in color, except for a few scattered pixels incorrectly detected as skin.

\section{The Proposed Skin Detector Evaluation}

This section involves the evaluation of the proposed skin detector efficiency. A skin detection process is never perfect and different users use varying criteria for performance evaluation. General appearance of size zones detected is one of the evaluation criteria. To quantify performance evaluation, True Positive (TP) and False Positive (FP), are computed for all pixels in the "skin classifier testing set" through skin detector testing. FP is the proportion of non-skin pixels classified incorrectly as skin, whereas TP is the proportion of skin pixels classified correctly as skin. To evaluate the skin detector by two approaches (texture features only, and a combination of both color and texture features), a sample of 1119129 pixels are used in this evaluation (Table 2). The Accuracy [11][32] of the first skin detector performance is 0.33 whereas it is 0.988 for the second skin detector.

Table 2: True Positive and False Positive for skin detectors

\begin{tabular}{|l|c|c|}
\hline \multicolumn{1}{|c|}{ Skin Detector } & TP & FP \\
\hline Skin detector based on texture feature only & $70.51 \%$ & $64.34 \%$ \\
\hline Skin detector based on combing both texture and color features & $94.50 \%$ & $0.89 \%$ \\
\hline
\end{tabular}

\section{Discussion}

Considering the unconstrained nature of Internet images, the performance of the skin detector is surprisingly good. The best performance can detect $94.50 \%$ of skin pixels with an FP rate of $0.89 \%$, by combining both texture and color features Although there is no means to locate any two papers which used the same test sets, examining previously published results may be useful. The performance of the proposed skin detector in this research is compared with the performance of other skin detectors. The Bethe Tree Approximation of First Order Model proposed by Zheng et al [33] can detect $72 \%$ of skin pixels with a $5 \%$ FP rate, whereas the proposed Bayesian model by Jones and Rehg [14] can detect $69 \%$ at the same FPs. The recall rate of pixel-based skin color classification proposed by Gasparini et al. [11] is 92\%, while precision equals 39\%. Figure (12) shows a simple comparison among different skin detection approaches. These evaluation metric values indicate that the proposed skin detector outperforms and is the most reliable of all skin detectors mentioned above. 


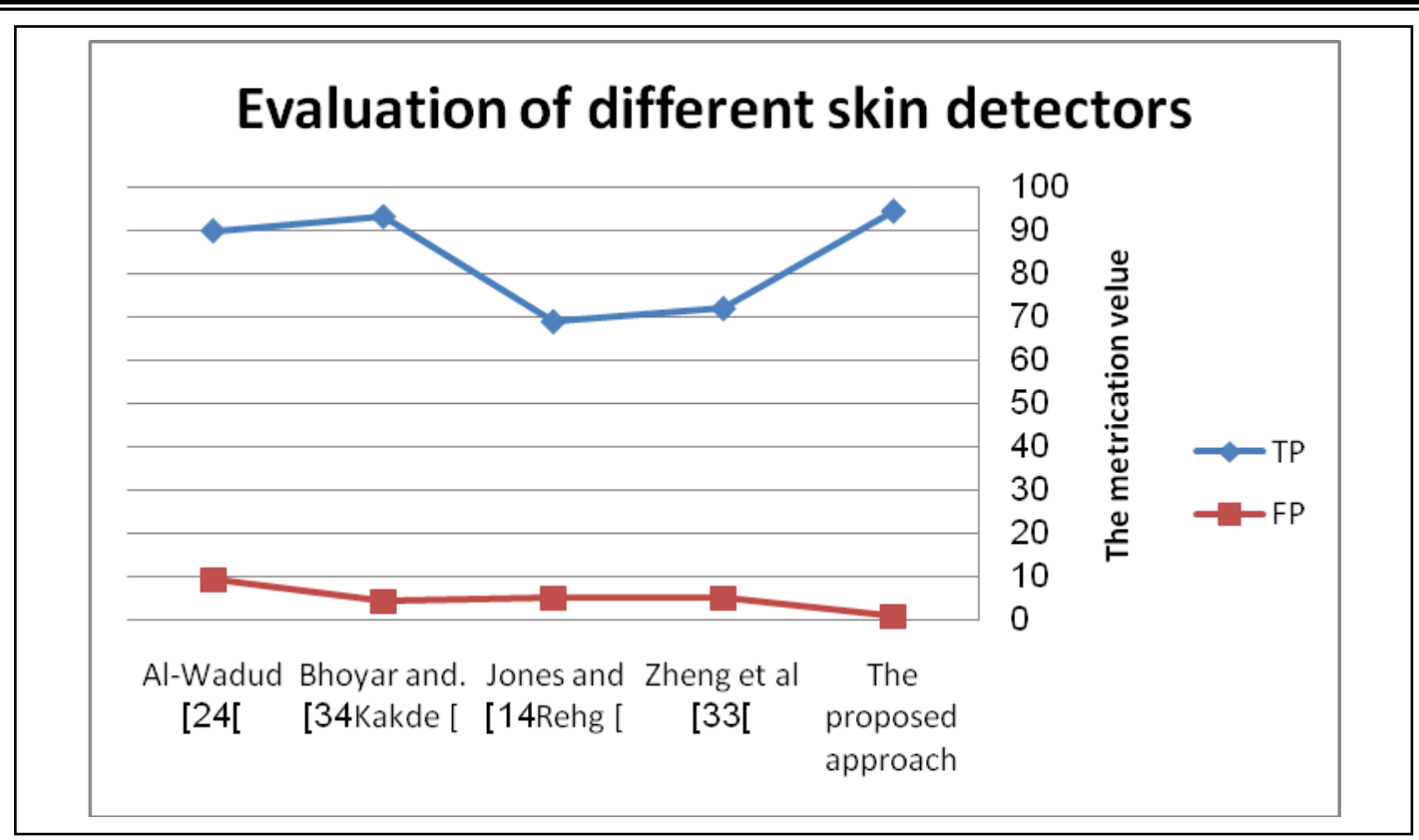

Figure 12: Evaluation of different skin detection approaches

\section{Conclusion and future work}

Skin detection is an important pre-process in many image analysis applications; hence, we proposed an improved skin detection method integrating both color and texture features to increase the reliability of skin detection using ANN. The neighborhood information of each pixel was also used through the training and testing phases. Two approach (texture-based skin detector and a combination of both color and texture features) were applied and tested. We have shown in this paper that a skin detector based on combined color and texture features can lead to an efficient and more reliable method for supervised skin detection compared with using pre-defined color tone rules or texture features only. The proposed detector reduces the FP rate to $0.89 \%$ with respect to based on texture feature-only skin detectors. A necessary future direction is to validate the proposed algorithms using a standard skin database data set. Such a method will enable us to compare our detection results with those presented by other authors for the same test images. Another improvement is adapting our approach to fuzzy logic technique using frequency domain. 


\section{References}

1) J. Kovac, P. Peer, F. Solina, "Human Skin Colour Clustering for Face Detection, In International Conference on Computer as a Tool", (EUROCON), Ljubljana, Slovenia, 2003, 22-24, September.

2) S.E. Umbaugh, R.H. Moss, W.V. Stoecker, "Automatic color segmentation of images with applications in detection of variegated coloring in skin tumor"s, IEEE Engng Med. Biol. 8 (1989) 43-52.

3) D. M. Gavrilla, "The analysis of human motion and its application for visual surveillance", Second IEEE Workshop on visual surveillance, 1999, pp. $3-5$.

4) M. Fleck D. A. Forsyth , C. Bregler C, "Finding Naked People", Proc. European Conf. Computer Vision, 1996, vol. 2, pp. 593-602.

5) R. C. Gonzalez ,R. E. Woods, "Digital Image Processing”, 2nd edition, Prentice Hall, Inc,2002.

6) E. S. Umbaugh "Computer Vision and Image Processing", Prentice Hall,1998.

7) S. K. Singh, D. S. Chauhan, M. Vatsa, R. Singh, "A Robust Skin Color Based Face Detection Algorithm", Tamkang Journal of Science and Engineering, Vol. 6, No. 4, 2003.

8) Y. C. Lin, H. W. Tseng, C. S. Fuh, "Pornography Detection Using Support Vector Machine", 16th IPPR Conference on Computer Vision, Graphics and Image Processing (CVGIP), Kinmen, 2003, 17-19 August.

9) Y. Chan, R. Harvey, D. Smith, "Building Systems to Block Pornography", In 2nd UK Conference on Image Retrieval: The Challenge of Image Retrieval (CIR'99), 1999, BCSEI Electronic Workshops in Computing Series, New Castle, UK, pp. 34-40, $25-$ 26 February.

10) V. Vezhnevets, V. Sazonov, A. Andreeva, "A survey on pixelbased skin color detection techniques", GRAPHICON03, 2003, PP. 85-92.

11) F. Gasparini, S. Corchs, R. Schettini, "Pixel Based Skin Colour Classification Exploiting Explicit Skin Cluster Definition Methods", In Proceedings of International Colour Association (AIC) 2005, Colour, Granda, Spain, pp. 543-546, 8-13 May.

12) R.L. Hsu, M. Abdel-Mottaleb, and A.K. Jain, "Facedetection in color images," IEEE Trans. on Pattern Analysis and Machine Intelligence, vol. 24, no. 5,2002, pp. 696-706. 
13) J. Ruiz-del-Solar, R. Verschae, "Robust Skin Segmentation using Neighborhood Information", ICI. Schalkoff R, 1999, Artificial Neural Networks, McGraw-Hill.

14) M. Jones, M. Rehg, "Statistical Color Models with Application to Skin Detecting", International Journal of Computer Vision (IJCV), Vol. 1, No. 46, 2000, pp. 81-86.

15) S. Ghouzali, S. Hemami M. Rziza, D. Aboutajdine, E. M. Mouaddib, "A skin detection algorithm based on discrete cosine transform and generalized Gaussian density", Image processing, ICIP 15th IEEE International Conference, 2008, ICIP08 IEEE p. 605-608.

16) A. Maskooki, E. Gunawan, C. B. Soh, K. S. Low, "Low frequency Domain Skin Artifact Removal Method for Ultra-Wideband Breast Cancer Detection", Progress in Electromagnetic Research, PIER 98, 2009,299-314.

17) D. Brown, I. Craw, J. Lewthwaite, "A SOM Based Approach to Skin Detection with Application in Real Time Systems", In Proceedings of British Machine Vision Conference (BMVC), 2001, Manchester,UK,10-13 September.

18) N. K. Al Abbadi et al, "Psoriasis Detection Using Skin Color and Texture Features", Journal of Computer Science Vol. 6, issue 6, pp. 626-630, ISSN 1549-3636,2010

19) A.Y. Taqa and H. J. Jalab," Increasing the Reliability of Fuzzy Inference System-Based Skin Detector", American Journal of Applied Sciences vol. 7, issue 8, pp. 1129-1138, ISSN 1546-9239, 2010.

20) A. Ahmed, M.Y. Javed, and U. Qayyum, "A robust fuzzy logic based approach for skin detection in colored images", International Association Of Science And Technology For Development ,Proceedings of The Eleventh IASTED International Conference on Artificial Intelligence and Soft Computing, Palma de Mallorca,2007, Spain, SESSION: Machine vision and intelligent robots table of contentsPages: 295-301 ,ISBN:978-0-88986-694-2 , ACTA Press Anaheim, CA.

21) H. K. Almohair, A. Ramli, A. M. Elsadig, H. J. Shaiful, "Skin Detection in Luminance Images using Threshold Technique", International Journal of The Computer, the Internet and Management Vol. 15\#1, 2007, pp 25 -32, January - April.

22) J. M. Zhiwei, Yao, W. Jiang, "Skin detection using color, texture and space information", Proceedings of the Fourth International Conference on Fuzzy Systems and Knowledge Discovery, 2007, 24-27 August, Haikou, Hainan, China, IEEE Computer Society, Volume 03, Pages: 366-370. 
23) A. A. Abin, M. Fotouhi, Sh. Kasaei, "Skin segmentation based on cellular learning automata", proceedings of the 6th International Conference on Advances in Mobile Computing and Multimedia, 2008, Austuria, ACM, Pages: 254-259.

24) M. A. Al-Wadud, O. Chae, "A Skin Detection Approach Based on Color Distance Map", EURASIP Journal on Advances in Signal Processing, Volume 2008, Article ID 814283,2008.

25) A. Conci, E. Nunes, J. J. Pantrigo, A. Sanchez, "Comparing color and texture-based algorithms for human skin detection", vol. 5, Computer Interaction, 2008, pp. 168-173.

26) M. M. Fotouhi, H. Rohban, and S. Kasaei, "Skin Detection using Contourlet Texture Analysis". In The $14^{\text {th }}$ Int'l CSI Computer Conference, 2009, CSICC, pages 367-372, Tehran, Iran, Oct.

27) B. Zafarifar, A. Martinière and H. N. Peter, "Improved Skin Segmentation for TV Image Enhancement, Using Color and Texture Features", IEEE International Conference on Consumer Electronics (ICCE2010) 2010, LasVegas, vol. p. 373-374, January.

28) Doukim and et al, "Combining Neural Networks for Skin Detection", Signal \& Image Processing : An International Journal (SIPIJ) Vol.1, No.2, PP. 1-11, 2011.

29) J. Verzani, J, "109impler - using R for Introductory Statistics", 2002, URL http://www.cran.R-project.org

30) Y. Chauvin and D. Rumelhart. Backpropagation: Theory, Architectures, and Applications. Lawrence Erlbaum, 1995, Online vertion.

31) S. N. Sivanandam, S. Sumathi, S. N. Deepa, "Introduction to Neural Networks using MATLAB 6.0", Tata McGraw-Hill Publishing, 2006.

32) T. Fawcett, "ROC Graphics: Notes and practical Consideration for Researchers", Technical Report HPL, Hp Lab, Palo Alto, California, USA, 2003.

33) H. Zheng, H. Liu M. Daoudi, "Blocking Objectionable Images: Adult Images and Harmful Symbols", Proceedings of IEEE International Conference on Multimedia and Expo, 2004, Taipei, Taiwan, 27-30 June.

34) K.K. Bhoyar and O.G. Kakde," Skin Color Detection Model Using Neural Networks and its Performance Evaluation", Journal of Computer Science Vol. 6, issue 9, pp. 963-968, ISSN 1549-3636, 2010. 